$\begin{array}{ll} & \text { Etnográfica } \\ \text { etnográfica } & \text { Revista do Centro em Rede de Investigação em }\end{array}$

Antropologia

vol. $18(3) \mid 2014$

Vol. $18(3)$

\title{
¿No aptos para vivir? Una aproximación etnográfica a las disputas por significar el territorio de un asentamiento de la ciudad de Córdoba, Argentina
}

Impróprio para viver? Uma aproximação etnográfica às disputas de significado sobre o território de um asentamiento da cidade de Córdoba, Argentina

María Victoria Perissinotti y Denise Zenklusen

\section{OpenEdition}

\section{Journals}

\section{Edición electrónica}

URL: https://journals.openedition.org/etnografica/3794

DOI: 10.4000/etnografica.3794

ISSN: 2182-2891

Editor

Centro em Rede de Investigação em Antropologia

Edición impresa

Fecha de publicación: 1 octubre 2014

Paginación: 481-498

ISSN: 0873-6561

Referencia electrónica

María Victoria Perissinotti y Denise Zenklusen, «¿No aptos para vivir? Una aproximación etnográfica a las disputas por significar el territorio de un asentamiento de la ciudad de Córdoba, Argentina»,

Etnográfica [En línea], vol. 18 (3) | 2014, Publicado el 09 octubre 2014, consultado el 10 febrero 2022.

URL: http://journals.openedition.org/etnografica/3794 ; DOI: https://doi.org/10.4000/etnografica.3794

\section{(c) (i) \&)}

Etnográfica is licensed under a Creative Commons Attribution-NonCommercial 4.0 International License. 


\section{¿No aptos para vivir? \\ Una aproximación etnográfica \\ a las disputas por significar \\ el territorio de un asentamiento \\ de la ciudad de Córdoba, Argentina}

\section{María Victoria Perissinotti y Denise Zenklusen}

Basado en un trabajo etnográfico realizado en un asentamiento de la ciudad de Córdoba (Argentina) este artículo propone analizar las disputas que mantienen distintos actores interesados en el proceso de definición y clasificación de un territorio. A partir de que el asentamiento en cuestión fue declarado por el Estado como inhabitable, se desata un conflicto que permite problematizar la clasificación de un territorio como contaminado. Partiendo del supuesto de que la definición de un territorio no remite únicamente a dimensiones materiales objetivas, sino que condensa las representaciones que los sujetos se hacen de él, buscamos mostrar cómo la lucha por clasificar el territorio puede ser comprendida como una disputa política. Con este objetivo, indagamos en las posiciones que asumen los sujetos involucrados, mostrando cómo esta disputa conlleva consecuencias significativas para estas personas.

PALABRAS-CLAVE: contaminación, territorio, etnografía, Argentina.

Impróprio para viver? Uma aproximação etnográfica às disputas de significado sobre o território de um asentamiento da cidade de Córdoba, Argentina - Baseado num trabalho etnográfico realizado num asentamiento da cidade de Córdoba (Argentina), este artigo propõe analisar as disputas mantidas por distintos atores interessados no processo de definição e classificação de um território. O asentamiento em questão foi declarado pelo Estado como inabitável, o que gerou um conflito que permite problematizar a classificação de um território como contaminado. Partindo do pressuposto de que a definição de um território não remete unicamente para dimensões materiais objetivas, mas condensa as representações que os sujeitos fazem dele, procuramos mostrar como a luta por classificar o território pode ser compreendida como uma disputa política. Com este objetivo, questionámos as posições que assumem os sujeitos envolvidos, mostrando como esta disputa acarreta consequências significativas para essas pessoas.

PALAVRAS-CHAVE: poluição, território, etnografia, Argentina.

PERISSINOTTI, María Victoria (vperissinotti@gmail.com) - Centro de Estudios Avanzados, Universidad Nacional de Córdoba, Argentina.

ZENKLUSEN, Denise (denisezenklusen@gmail.com) - Conicet-CIECS; Universidad Nacional de Córdoba, Argentina. 


\section{A FINALES DE 2009 LA MUNICIPALIDAD DE CÓRDOBA ${ }^{1}$ SANCIONA UN} decreto en el que se declara la "inhabitabilidad del suelo" ${ }^{2}$ sobre el que se encuentra construido Los Pinos, un asentamiento (Merklen 2005) ubicado en una zona periférica del sur de la ciudad y habitado casi en su totalidad por inmigrantes provenientes de Perú, Bolivia y Paraguay. El mismo decreto señala además la recomendación de trasladar a los vecinos que allí viven a un predio "no contaminado". Sin embargo, no se especifica ni el lugar, ni el momento, ni la manera en que se realizaría el traslado.

En este contexto, surgen entre los habitantes de Los Pinos posturas enfrentadas que se estructuran en la redefinición de dos "facciones": una que quiere ser relocalizada y otra que se niega al traslado. ${ }^{3}$ Mientras la primera inició negociaciones con los funcionarios del Estado para concretarlo, la segunda facción se opuso a esta posibilidad porque descreen de la afirmación de que los terrenos serían inhabitables. Así, esta facción protagonizó enfrentamientos con el gobierno municipal, que insiste en que deben abandonarlos.

Partiendo del supuesto de que la noción de territorio no refiere únicamente a una dimensión geográfica que pueda definirse de antemano como un espacio objetivo que se encuentra por fuera de los sujetos, sino que por el contrario, el espacio es modelado por la sedimentación de prácticas, representaciones y vivencias (Lefebvre 1974), en este artículo indagamos en las disputas que los distintos agentes interesados (Lenoir 1993) llevan adelante para definir la clasificación del espacio en el que viven. Atendiendo a la propuesta de Lefebvre (1974), buscamos detenernos en el análisis de la producción del espacio en lugar de conformarnos sólo con describir las formas espaciales. Desde este enfoque, recuperamos entonces la dimensión temporal, historizando los procesos en los que se enmarca el caso analizado, con el objetivo de dilucidar cómo estas disputas pueden comprenderse en términos de "luchas políticas" (Bourdieu 1999: 244).

Con este objetivo, en el primer apartado describimos brevemente la situación que da origen a las disputas analizadas. En el segundo, caracterizamos la historia de los procesos de urbanización de la ciudad de Córdoba, fundamentales para comprender los sentidos y las prácticas que se desataron en Los Pinos luego de que fuese declarado el traslado. Siguiendo a Prévôt Schapira (2001),

I Córdoba es una de las tres ciudades más grandes de la Argentina. Es la capital de la provincia homónima, ubicada al centro norte del país. Municipalidad corresponde a la institución estatal que gobierna cada ciudad del país. Es la unidad mínima de gobierno.

2 El decreto establece que no se puede vivir sobre esos terrenos puesto que se encuentran contaminados. A lo largo del artículo, veremos a qué hace referencia esta categoría y la complejidad que adquiere. 3 Moacir Palmeira entiende a las facciones como "una forma de organización política" definida por "unidades de conflicto, cuyos miembros son agrupados por un líder en base a principios variados". Según este autor, uno de los rasgos que las caracteriza es que no son permanentes. Sin embargo, aclara, esto "no significa que no puedan persistir por un largo período de tiempo" (Palmeira 2003: 33). 
entendemos que estos procesos no son exclusivos de dicha ciudad sino que se insertan en el modo particular en que se están pensando las ciudades latinoamericanas. El concepto de segregación (Marcuse y Van Kempen 2000) ofrece herramientas centrales para comprender las disputas analizadas.

Esta historización nos permite, en el tercer apartado, arrojar luz sobre la dimensión política que envuelve la lucha de los actores en el proceso de clasificación del lugar en el que viven. Problematizamos la noción de contaminación como una cualidad objetiva de un territorio para reintroducirla en el marco de las luchas que distintos sectores de la sociedad entablan por definir los territorios que habitan. Analizamos entonces cómo la decisión del Estado acerca de las posibilidades que algunas personas tienen de habitar determinados espacios, lejos de ser interpretada y aceptada pasivamente por los actores afectados, se convierte en objeto de luchas políticas.

Este artículo es producto de un trabajo de campo etnográfico desarrollado entre el 2011 y el 2012 en el barrio señalado. El mismo fue realizado en el marco de una investigación acerca de los modos en que las prácticas de comunicación se relacionan con la política. Nuestro trabajo de campo consistió en la observación participante de diferentes actividades y en el registro de conversaciones. Dentro de éstas últimas, mientras que algunas fueron pautadas con nuestros informantes, la mayoría se desarrolló de manera informal durante el trabajo de campo. Con respecto a las actividades de las que participamos, cabe destacar la concurrencia a asambleas semanales organizadas por la facción que se quiere quedar habitando el barrio y a actividades comunitarias tales como festividades y celebraciones barriales. Así, logramos establecer vínculos significativos con vecinos pertenecientes a ambas facciones. La perspectiva metodológica resultó central para desentrañar los sentidos que los diversos actores le otorgan al conflicto que abordamos, permitiéndonos desnaturalizar los presupuestos con los que suelen abordarse estas problemáticas.

\section{LA CONTAMINACIÓN: DE FACCIONES Y DESCONFIANZAS}

El conflicto por la contaminación de los suelos sobre los que viven estas personas se convirtió en noticia durante algunos meses. En ese tiempo, los medios de comunicación desplegaron una serie de acusaciones cuestionando a los vecinos que decidieron permanecer habitando el barrio. Pese a que se había "comprobado" que el terreno estaba contaminado, la prensa sostenía que estas personas se empecinaban en seguir viviendo allí, exponiéndose a los riesgos que esto implicaba. ${ }^{4}$ Ahora bien, ¿no existirán razones para que estos vecinos

4 Así titulaba el diario local de mayor tirada de la ciudad de Córdoba las noticias referidas a la problemática de Los Pinos: "El barrio que crece sobre residuos patógenos" (La Voz del Interior, 06 de septiembre de 2009); "Cómo se pobló la zona del basural" (La Voz del Interior, 06 de septiembre [continúa] 
decidan permanecer habitando esos terrenos?, ¿será sólo por "ignorancia” que mantienen su postura?

El barrio Los Pinos es un asentamiento conformado por dieciocho manzanas de veinticuatro lotes cada una, perfectamente diagramadas y separadas entre sí por calles de tierra, sin veredas y por las cuales casi no transitan autos. Según un censo que se realizó en el barrio en diciembre de 201l, viven allí alrededor de 350 familias compuestas por matrimonios jóvenes con dos o tres hijos, en su mayoría provenientes de Perú, Bolivia y Paraguay. Estas personas argumentan la decisión de migrar a partir de la oferta laboral y educacional que ofrecería la Argentina, y en particular la Ciudad de Córdoba, ya que muchos de ellos cuentan allí con familiares que migraron anteriormente. ${ }^{5}$ En términos socioeconómicos se trata de flujos de carácter laboral, que presentan "un alto grado de precariedad y vulnerabilidad” (Falcón Aybar y Bologna 2013: 242). Así, la mayoría de las mujeres se desempeña como empleada doméstica, mientras que los varones están abocados al rubro de la construcción.

Asociado a la fuerte precarización de estas trayectorias laborales, un creciente número de migrantes latinoamericanos comenzó a instalarse en las zonas periféricas de la ciudad. Fue así que, a finales de 2008, un grupo de personas decidió construir sus viviendas en un predio que, hasta la década del sesenta, había funcionado como un basural a cielo abierto. Ésta constituye una de las características que con mayor recurrencia nos señalaban nuestros interlocutores. Además, según nos comentaron, en "esa época no se separaba lo que se tiraba", motivo por el cual también hay presencia de "residuos patógenos". Actualmente, al recorrer el barrio se pueden observar estos residuos: mezclado entre la tierra, y sobre todo en las calles, se observan desde restos de zapatos, muñecos y ropa vieja, hasta vidrios, jeringas, gomas para sacar sangre y ampollas. Estos últimos corresponden a lo que los vecinos denominan residuos patógenos.

Arguyendo la existencia de este basural y de la supuesta contaminación que acarrearía para las personas que allí viven, la Municipalidad de Córdoba firma el decreto, a fines de 2009, en el que se declara la inhabitabilidad de esos suelos. Los concejales, los médicos y la trabajadora social del dispensario hacen

[continuación] de 2009); "Hay un riesgo de muerte de quienes viven allî" (La Voz del Interior, 26 de mayo de 2011). Nos interesa recuperar estas frases puesto que resultan significativas para dar cuenta del modo en que evaluaban la situación los medios de comunicación.

5 La presencia de personas provenientes de países del sur de Latinoamérica resulta significativa en Argentina desde mediados del siglo XX, siendo la Ciudad de Córdoba uno de los destinos que atrae mayor cantidad de migrantes. Desde las últimas décadas del siglo XX se profundizaron los niveles de pobreza, exclusión y precariedad laboral en los países de la región. Bajo este escenario, la migración se ha transformado en una estrategia más de subsistencia para un importante número de familias. Así, según datos del último censo nacional de población del año 2010, del total de la población extranjera que vive en la provincia de Córdoba, más del 75 por ciento proviene de la región sudamericana. 
eco de esta decisión, afirmando tajantemente que "esa gente no puede vivir ahí”. En este panorama, la contaminación adquiere entre los vecinos del barrio diferentes sentidos contrapuestos entre sí y que se pueden agrupar en torno a dos grandes nociones: la contaminación como un verdadero riesgo para los habitantes del barrio y la contaminación como una excusa que utilizan quienes tienen intereses ${ }^{6}$ en esas tierras, para sacarlos de ahí. Pero ¿cómo surgen estas posturas?, ¿en qué se basa la desconfianza de quienes argumentan esta posición?

Claudia, una vecina perteneciente a la facción que se quiere ir, recuerda que cuando los vecinos comenzaron a asentarse en estos terrenos, se acercó a ellos la asistente social de la zona advirtiéndoles que allí anteriormente existía un basural y que, por ese motivo, había riesgos de contaminación. En consecuencia, nos explica Claudia, desde el dispensario se le encomienda a la Universidad Nacional de Córdoba la realización de un análisis del suelo.

"Pedimos que se hagan unos estudios para ver el grado de contaminación, porque la gente se estaba acercando cada vez más a esa zona [los terrenos del ex basural] y estaba construyendo. La Universidad realizó tres pozos en distintas partes y tomó muestras de eso y dio que esto estaba contaminado. Este informe fue casi al principio, cuando no había prácticamente nadie viviendo en el barrio. El informe daba terrenos no aptos para vivir" [Claudia, junio de 2011 ].

A medida que el barrio comienza a crecer y a raíz de los resultados arrojados por los análisis del suelo, la contaminación como un riesgo para la salud de quienes viven en Los Pinos se convierte en un tema que circula permanentemente en el barrio y también en los medios de comunicación de la ciudad. Sin embargo, las imprecisiones y las dudas persisten dado que, desde el Estado, en ningún momento se les explica qué significa esta contaminación. Sólo recién avanzado nuestro trabajo de campo los vecinos nos comentaron a qué se refieren cuando se habla de terrenos "no aptos para vivir". Los análisis arrojan que la tierra contiene, producto de haber funcionado como un basural, cinco metales pesados: plomo, cromo, estaño, zinc y un quinto que nadie pudo precisar cuál es. La contaminación se asocia a estos metales que, según les informaron, pueden presentarse en la sangre de las personas expuestas a ellos. Sin embargo, los vecinos desconocen qué efectos podría acarrear la presencia de alguno de estos elementos en sus cuerpos y cuán perjudicial podría ser para su salud.

Tal como muestran Auyero y Swistun (2007: 140), una de las características centrales del "sufrimiento ambiental" al que se ven expuestos los sectores empobrecidos que habitan espacios contaminados remite a la "incertidumbre".

6 El uso de cursivas indica que la palabra señalada responde a la utilización que de ella hacen los sujetos de esta investigación, en tanto categoría nativa. 
Ésta se encuentra asociada, según los autores, a los constantes anuncios del Estado prometiendo traslados hacia espacios no contaminados; a las confusas intervenciones de los médicos y a los rumores sobre los diferentes intereses económicos que habría detrás de los terrenos.

Así, el tema de la salud se convierte en una dimensión central desde la cual se puede comprender la posición de quienes quieren irse del barrio. Ellos creen que efectivamente las tierras están contaminadas y consideran que la única opción que tienen es irse por la salud de sus hijos. Al respecto, una vecina nos comentaba:

"Si a mí me dan un lugar mejor yo me voy, sobre todo por la salud de mis hijos. Yo les quiero dar a ellos un futuro mejor, que puedan tener algo mejor [...] Yo lo que quiero es que nos vayamos a un terreno limpio... Lo único que queremos es que la Municipalidad nos garantice un terreno limpio y después nosotros lo pagamos en cuotas, eso es todo lo que le pedimos" [Claudia, junio de 2011].

En oposición a esta postura, quienes pertenecen a la facción que se quiere quedar, manifiestan abiertamente que ellos "no creen en la contaminación" dado que desconfían del Estado. De este modo, rechazan los análisis de la tierra porque intuyen que, detrás de ellos, se esconden intereses inmobiliarios por parte de los funcionarios del gobierno. Así, un vecino nos explica:

"Una vez que ya estábamos acá, que ya estaba limpio, todo, ahí la asistenta social del dispensario, la que más hizo para que nos saquen de acá, empezó a decir que esta tierra estaba contaminada, que había que hacer análisis porque la gente se iba a morir. Ahí la Universidad hace un análisis. Mientras los están haciendo, el ingeniero [encargado de los análisis] me dijo en mi cara: 'Mire Juan, en cualquier picaporte de cualquier oficina de la Municipalidad de Córdoba hay más contaminación que en Los Pinos’ [...] Al día siguiente, aparece en todos los medios que Los Pinos está contaminado, que la gente se está muriendo, iporque nos estábamos muriendo ya eh! Y ahí aparece [este ingeniero] diciendo lo mismo, que estábamos contaminados. Entonces, ¿Cómo puede ser? [...] Igual nosotros nunca creímos en esos análisis, nunca creímos $[\ldots]$ ya te voy a explicar por qué. Lo que nosotros sabemos es que estas tierras tienen un gran interés inmobiliario" [Juan, febrero de 2012].

A raíz de la desconfianza en estos primeros estudios, un grupo de vecinos exige a la Municipalidad que realice nuevos análisis de la tierra. Pero esta vez, establecen una condición: que sean sus propios habitantes quienes caven los pozos para recoger las muestras de tierra. En un principio, la Municipalidad 
accede pero este acuerdo no se cumple ya que meses después aparecen los resultados "sin que los vecinos hayan realizado los pozos". Desde la perspectiva de quienes quieren quedarse, este hecho no hace más que confirmar que existen intereses alrededor de las tierras de Los Pinos y que, por lo tanto, no se puede confiar en ninguno de los análisis. Es así que califican al tema de la contaminación como un verso. ${ }^{7} \mathrm{Al}$ preguntarles por esta clasificación, una vecina nos comenta: "O sea, es un verso. Es un verso, pero como se hizo público... Otros decían que era mala intención, porque tenían algún negociado con los dueños de la tierra, porque iban a vender, no sé qué historia" [Sandra, mayo de 2012].

Entender la contaminación como una situación de riesgo en términos de Luhmann (1992) ayuda a comprender la problemática abordada. Según este autor, no se puede pensar "que los cálculos de riesgo tengan posibilidades de suscitar consenso, inclusive en el caso de situaciones específicas" (Luhmann 1992: 48). Por el contrario, la evaluación de los riesgos y la disposición a aceptarlos se trata de un problema social puesto que "algo que es tenido por lo mismo por distintos observadores, genera informaciones muy diversas para ellos" (Luhmann 1992: 67). El hecho de que distintas personas evalúen la situación de manera contradictoria, haciendo que surjan posiciones tan diferentes entre sí, sólo puede comprenderse si entendemos que aún una misma situación puede ser observada por distintos actores de manera diferencial.

Asimismo, los aportes de Mary Douglas (2002 [1966]) ayudan a iluminar esta situación. Siguiendo el planteo de esta autora, entendemos que los riesgos no son naturales sino que son socialmente construidos. El riesgo entraña, según esta autora, elementos culturales que llevan a los individuos a percibir a una situación en esos términos. Así, puede entenderse que la clasificación que el Estado intenta imponer sobre el territorio de Los Pinos como un lugar riesgoso, no necesariamente sea aceptada por todos.

Teniendo en cuenta estos aportes, y asumiendo que en la definición del espacio existen luchas entre agentes sociales interesados, se puede comprender entonces que la postura de aquellos vecinos que manifiestan querer quedarse habitando el barrio responde a razones más complejas que la mera ignorancia que les atribuyen los medios de comunicación y el Estado. Frente a la afirmación de que los terrenos de Los Pinos serían inhabitables, quienes se quieren quedar sostienen que la contaminación es un verso.

Para pensar esta articulación resulta necesario advertir que históricamente el Estado ha acudido a la noción de contaminación como una manera de justificar sus políticas públicas de relocalizaciones. La noción de interés inmobiliario esgrimida por aquellos que se quieren quedar se torna central para comprender 
por qué estas personas desconfían de los análisis de suelo y afirman que, para ellos, la contaminación proclamada por el Estado no sería tal. Atender a las características históricas que los procesos de urbanización han adquirido en América Latina en general y en la ciudad de Córdoba en particular resulta fundamental para comprender las razones que se articulan detrás de este planteo.

\section{LOS PROCESOS DE URBANIZACIÓN EN CÓRDOBA}

En los últimos tiempos, numerosos autores (Caldeira 2007, 2011 ; Marcuse y Van Kempen 2000; Schteingart 2001 [1990]; Prévôt Schapira 2001; Lacarrieu y Thuillier 2001) han trabajado la noción de segregación para dar cuenta del modo particular en el que se están pensando las ciudades latinoamericanas. Con este concepto, los autores se refieren al resultado de aquellos procesos de planificación de las ciudades que configuran el espacio urbano de manera tal que se puede distinguir en ellas una segmentación de los territorios ocupados, según los distintos grupos sociales. En estos procesos el Estado ocupa un papel central, interviniendo en complicidad con los sectores privados en pos de liberar terrenos para su edificación y explotación comercial. En Argentina la fuerte polarización económica se vio entonces reflejada en la geografía urbana. La interacción entre la economía, las políticas estatales y la acción de los actores políticos dio como resultado espacios de segregación urbana (Auyero 2007).

En concordancia con aquello que sucede a nivel nacional, el Estado de la Provincia de Córdoba ha jugado un papel activo en las relocalizaciones de villas y asentamientos, no desde una política habitacional que busque dar respuesta a las necesidades de los sectores populares, sino más bien apuntando al crecimiento del valor comercial de la zona céntrica de la ciudad. Entre el 2003 y el 2008, el gobierno provincial implementó un programa de relocalizaciones masivas denominado "Mi Casa, Mi Vida" a través del cual se trasladaron setenta villas de la ciudad (Bermúdez 2009). Los predios en los que fueron reubicadas estas personas se encuentran en las periferias de la ciudad y presentan serios problemas en términos de servicios, en especial de transporte. Estas características, sumadas a la compulsividad con la que fueron desalojadas las familias que se negaban a trasladarse, permiten comprender la desconfianza que los vecinos de Los Pinos mantienen hacia el Estado. Además, entendemos que la asociación entre el Estado y los capitales privados corresponde a aquello con lo que algunos vecinos vinculan la noción de interés inmobiliario que articula esta desconfianza, categoría a partir de la cual quienes quieren quedarse argumentan su posición. Es decir, dado que el Estado históricamente ha demostrado intereses en espacios habitados por sectores populares, a ojos de los vecinos de Los Pinos, no sería extraño que también los tenga sobre sus terrenos. Es por esto que un gran sector de su población descree de los análisis de suelo que realizó la Municipalidad. 
Sumado a esto, resulta importante detenerse a analizar cómo históricamente en Argentina las políticas públicas habitacionales han estado asociadas a la idea de contaminación. Según Auyero, "la perversa combinación de abandono y represión" hizo que las representaciones oficiales sobre la villa giraran en torno a ésta como un espacio "de contaminación, como una otredad radical” (2007: 26). Estas representaciones se extendieron al resto de la sociedad, de modo que se genera una naturalización del vínculo entre pobreza y contaminación (Carman 2011).

Específicamente en la provincia de Córdoba, durante el programa "Mi Casa, Mi Vida”, los funcionarios argumentaron la necesidad de relocalizar dichos asentamientos debido a que los terrenos que habitaban se encontraban contaminados (Bermúdez 2009). Resulta interesante ver de este modo, cómo desde el Estado se asocia a los asentamientos y a las villas con nociones que remiten a la contaminación, la suciedad y la necesidad de "limpiarlos". ${ }^{8}$

En Córdoba esto se relaciona con el proceso de modernización de la ciudad, que desde fines de siglo XIX se fundamentó en los conceptos de "higiene, salubridad, orden, estética” (Boixadós 2000: 124). Podemos observar cómo este discurso trasciende esa época particular y continúa funcionando a través de planteos que ubican a la noción de contaminación asociada a los espacios habitados por los sectores populares. Tal es el caso del programa "Mi Casa, Mi Vida”, en el que subyacían ciertas nociones que remitían a cuestiones sanitarias y de higiene. Uno de los funcionarios coordinadores de dicho programa sostuvo en un discurso: "es importante aclarar que nosotros no destruimos nada. Generamos mucha vida [...] los lugares que están contaminados se curan" (Payró y Montoya 2007: 35-36). Esto permite comprender que la noción de contaminación, permanentemente referida, tanto por el Estado como por los propios vecinos, para describir o disputar la situación de Los Pinos, adquiere significado en relación al discurso higienista que fundamenta el accionar de estas políticas públicas.

En este sentido, la presencia histórica de esta noción como una manera de justificar las políticas de relocalizaciones de los sectores populares que ocupan espacios con alto valor inmobiliario resulta llamativa. Así se puede comprender que algunas personas pongan en duda la veracidad de los análisis y, con ello, disputen la clasificación del espacio que habitan en términos de un espacio contaminado.

Para el Estado y para aquellos que se quieren ir, los análisis científicos de la tierra aparecen como los garantes de la objetividad de la contaminación. Sin embargo, como mostró Douglas (2002 [1966]), la información técnico-científica no es lo único que se toma en cuenta a la hora de definir si una situación

8 En estos términos se refirió un funcionario del Estado provincial a su tarea en relación a las relocalizaciones masivas implementadas por el programa mencionado. 
constituye un riesgo o no. Para tomar decisiones las personas nos basamos no sólo en la información que se tiene respecto de algo sino también en los elementos simbólicos. Así, como señalábamos, el riesgo constituye una construcción cultural en la cual la información no es lo único que se toma en cuenta. Además, los vecinos tienen un conocimiento vago de los resultados de los análisis. De hecho, el informe no llegó a manos de ellos, sino sólo a través de terceros. En ninguno de los dos análisis les explicaron qué significa la presencia de estos metales ni especificaron con claridad qué daños podían ocasionar a su salud. Las dos instituciones que los realizaron se limitaron a exponer de manera técnica las concentraciones de cada metal que se encuentran en los lotes analizados. De este modo, si bien todos hablan del plomo en sangre como el mayor riesgo que acarrearía la contaminación, la mayoría desconoce qué es lo que realmente produce tenerlo.

\section{DE TIERRAS Y RELACIONES CONTAMINADAS}

En la visibilización de los problemas sociales siempre se ponen en juego "apuestas de definiciones y de clasificaciones que producen los agentes interesados" (Lenoir 1993: 72). En este apartado, buscamos entonces analizar de qué manera la contaminación del espacio sobre el que construyeron sus viviendas estas familias se convierte en objeto de disputas por clasificar un territorio. Como veremos, dicha disputa no remite únicamente a la materialidad de los espacios, sino que condensa la construcción que los propios sujetos realizan a partir de los significados que le otorgan. Esto se puede comprender si entendemos que el "territorio es una noción plenamente histórica y política" de modo que "ni los aspectos del territorio ni del paisaje que lo marca y le confiere identidad aparecen como pre-existentes o "naturales"' (Segato 2006: 134).

En el marco de esta lucha de clasificaciones, las dos posturas esgrimidas son legitimadas apelando a diferentes construcciones de sentido. Por un lado, quienes afirman que los vecinos deben abandonar el terreno legitiman su posición en la supuesta objetividad científico-técnica que brindarían los análisis del suelo. Por el otro, aquellos que se quieren quedar argumentan su decisión a partir de la noción de esfuerzo. Como señalábamos, se puede comprender la existencia de estas dos posturas encontradas en torno a la contaminación a partir de percibir que, sobre el espacio objetivo, los actores imprimen representaciones subjetivas que forman parte inseparable de los sentidos que dicho espacio adquiere. Así, en Los Pinos "no hay claramente un único, monolítico, punto de vista $[\ldots]$ sobre la contaminación y sus efectos en la salud. Las percepciones van desde la obvia negación a la crítica consciente, de las dudas a convicciones profundamente arraigadas" (Auyero y Swistun 2007: 141).

La noción de contaminación de las tierras que estructura la percepción de aquellos que se quieren ir se encuentra estrechamente relacionada con la que 
postula el Estado. Ésta se vincula con la existencia del basural, los residuos que de él quedaron y los problemas en la salud que esto acarrearía. Los sentidos que implica esta clasificación los pudimos observar en un cartel colgado en la sala de espera del dispensario.

"En la pared había dos carteles, hechos a mano sobre papel afiche. Uno representaba un enorme basural, personificado como un monstruo con cara de malo y enojado y unas nubes que se tapaban los oídos, los ojos y la boca, representando el no oír, no ver, ni escuchar" [registro de campo, 07/07/2011].

Estos sentidos adquieren relevancia en tanto se encuentran en la base de la explicación que dan aquellos que se quieren ir cuando deben argumentar su decisión. La presentación del basural como un monstruo simboliza la peligrosidad que representaría la contaminación de las tierras. Por otro lado, la referencia al no ver, no oír y no escuchar habla de aquello que, desde el Estado, entienden como la negación de reconocer, por parte de los vecinos que se quieren quedar, que la contaminación es un hecho objetivo.

Estas representaciones son mantenidas por la facción que se quiere ir ya que confían en los funcionarios del Estado y, por tanto, en la afirmación de que allí no se puede vivir. Es decir, estas personas no consideran la posibilidad de que el Estado (asociado además a los médicos del dispensario y a la asistente social) les pueda mentir. Ellos afirman que la tierra efectivamente está contaminada y que esto implica serios problemas para la salud de sus hijos.

Este peligro les es recordado constantemente por los médicos del dispensario en el que se atienden. Según nos comentan, cada vez que acuden allí, los doctores atribuyen sus enfermedades al hecho de vivir sobre un basural. Sin embargo, al asociar directamente los problemas de salud a la contaminación, sin reparar en las precarias condiciones en las que viven, los médicos del Estado parecen inculparlas por sus afecciones.

La asistente social encargada de esa zona también mantiene una relación conflictiva con quienes decidieron quedarse viviendo allí. En declaraciones a la prensa, esta mujer acusaba a los vecinos de negligencia señalando que "se les dijo que ese lugar no era habitable, pero no hicieron caso. El problema ahora es que están decididos a quedarse sobre el basural". ${ }^{9}$

En el marco de la disputa analizada, quienes quieren quedarse habitando el barrio buscan clasificar esta situación de un modo diferente a los médicos y la trabajadora social y sostienen que desde el dispensario los discriminan 
por decidir quedarse. Con respecto a esto, una vecina que se quiere quedar viviendo en el barrio nos comentaba:

"Los del dispensario nos discriminan. Nos discriminan porque ellos quieren que nos vayamos, ellos nos dicen que no tenemos que estar viviendo acá porque esto está contaminado [...]. Ellos quieren que nos vayamos, no quieren que vivamos acá. Por ejemplo, yo tengo asma, y ahí me dijeron que tengo asma por vivir acá; pero de toda una vida que yo tengo asma no de dos años nomás" [Mari, mayo de 2011].

La noción de discriminación esgrimida por quienes quieren quedarse es de alguna manera utilizada para defender su posición. Al no tener demasiadas posibilidades de elegir en dónde residir, deben recurrir a una serie de justificaciones que les permitan permanecer en ese lugar. El hecho de que la mayoría de los habitantes de este barrio sean migrantes no resulta un dato menor en relación a este proceso. Terrones Ribas (2005: 204) señala que, dada su pertenencia de clase, los migrantes sólo pueden aspirar a cierto segmento del mercado de la vivienda que se corresponde con "zonas degradadas" a las cuales se accede a través del mercado informal.

Así, en los últimos años, asociado a las trayectorias laborales fuertemente marcadas por la precarización y la vulnerabilidad, se produjo un desplazamiento de los migrantes latinoamericanos a zonas periféricas de la ciudad de Córdoba (Falcón Aybar y Bologna 2013). Mientras que en las últimas décadas del siglo XX los y las migrantes latinoamericanos se asentaban en barrios tradicionales del centro de la ciudad, en la actualidad la imposibilidad de acceder a viviendas en esos lugares los desplaza hacia las zonas urbano-marginales. $\mathrm{El}$ acceso a la casa propia no está dado para estas personas a través del mercado inmobiliario formal sino que se vincula con otros espacios ubicados en la periferia de la ciudad. En su mayoría son terrenos fiscales que hasta el momento de su ocupación constituían terrenos baldíos y que se presentan como una alternativa frente a la urgencia de conseguir un lugar dónde vivir.

Pese a que la estrategia de ocupación es común a un importante conjunto de la población de los sectores populares, los asentamientos construidos por migrantes en la ciudad de Córdoba presentan características particulares que resulta importante analizar. A nuestro entender, éstas se relacionan estrechamente con el hecho de que, para los migrantes, estos espacios no son concebidos como transitorios sino que se constituyen como el lugar definitivo de su residencia.

De este modo, dado que no tienen margen de opción, pero como también saben que es posible que el suelo esté contaminado, los vecinos de Los Pinos deben realizar un trabajo social constante para disputar esta clasificación. Este trabajo va desde prácticas materiales sobre la tierra, como poner camionadas 
de tierra limpia, hasta las prácticas simbólicas de lucha de clasificaciones. Veremos a qué se refiere cada uno y cómo ambos tipos de apuestas se encuentran indisociados.

Frente a las acusaciones por no abandonar el lugar, estas personas constantemente evocan el gran esfuerzo realizado en construir no sólo sus viviendas, sino también su barrio, como otra de las razones por las cuales sería legítimo su reclamo por permanecer en esas tierras. En sus discursos, la noción de esfuerzo aparece como un argumento por el cual ellos se niegan a abandonar sus hogares.

"Ellos [los políticos] porque no saben todo el esfuerzo que nosotros hicimos para construir nuestra casa, muchas veces sacando el pan de la boca a nuestros hijos, y con el frío, con el calor, con el viento. Porque ellos no saben nada, si viven en countries, no saben lo que es. Ellos tienen agua caliente, tienen todo, no pasan frío, no saben lo que ha sido" [Sandra, mayo de 2011].

Con este registro observamos cómo funciona la categoría referida: el esfuerzo de los vecinos se contrapone a la liviandad con la que los políticos y el Estado abordan la problemática de Los Pinos. A estos relatos se suma la afirmación de que, en los comienzos, los terrenos estaban tapados de yuyos y de basura, por lo que tuvieron que limpiarlos. Para esto, nos cuentan que alquilaron entre todos camiones que sacaban la tierra con residuos y contrataron a otros que depositaban tierra limpia.

"Cuando construimos nuestra casa, que alquilamos máquinas, saqué de todo, saqué jeringas, saqué gomitas para sacar sangre, vidrios, saqué de todo. Lo que hicimos fue limpiar todo el terreno cavando un pozo [...] Limpiamos en profundidad, compramos y rellenamos con tierra limpia y ahí construimos nuestra casa" [Mari, mayo de 2011].

La categoría de tierra limpia aparece en este relato oponiéndose a la noción de contaminación. Para los vecinos, la acción de haber limpiado sus terrenos (como este trabajo material sobre la tierra del que hablábamos) funciona como un argumento que se contrapone a la clasificación que mantiene el Estado acerca de Los Pinos como un territorio inhabitable. Desde sus concepciones, sacar la basura, limpiar en profundidad y rellenar la tierra funcionan como acciones que les garantizan la posibilidad de permanecer en un terreno habitable. Estas prácticas entran en juego también simbólicamente en la lucha por clasificar el territorio. Así se puede comprender que la contaminación no pueda sancionarse por decretos, sino que forma parte de una constante disputa entre agentes sociales interesados.

Otro aspecto que resulta fundamental para analizar el modo en que la facción que se quiere quedar despliega su argumento en pos de fundamentar su 
presencia allí remite al material con el que se encuentran construidas la mayor parte de sus viviendas: ladrillos y cemento, a los que se refieren como material noble. En el marco de la lucha por clasificar sus terrenos, esto adquiere sentidos simbólicos fundamentales. El material remite al tipo de espacio que se quiere construir. Mientras que las viviendas de madera (a las que denominan despectivamente chozas) se asocian a las villas y los asentamientos; el material noble simboliza la construcción de un barrio.

Consideramos que, en el marco de este conflicto, la distinción entre barrio y asentamiento no resulta menor puesto que ser un barrio implica diferenciarse de otros modos de ocupar la tierra. Es decir, implica no ser una villa ni ser un asentamiento, de modo que no deberían ser objeto de relocalizaciones o traslados. Y en este sentido, el territorio mismo constituye parte de una disputa: mientras que la Municipalidad no ve en ese espacio sino un basural, terrenos inhabitables; quienes construyeron allí sus viviendas se esfuerzan en demostrar que ese espacio adquiere la categoría de barrio. Estos relatos discuten, tal como se ve a continuación, la noción de contaminación propuesta por el Estado, por los medios de comunicación y por la facción de quienes quieren irse.

"Lo llevé a mi casa al de noticiero, porque acá siempre que vienen filman en un descampado, lleno de basura. Vienen y muestran, filman la casa que está cerca del basural. Y acá no es así. Nosotros trabajamos mucho desde que vinimos [...] No muestran estas casas que están todas bien. No se acercan para estos lados. [...] Yo les mostré mi casa que tiene todo pasto crecido, mejor que un country está" [Mari, mayo de 2011].

Aquello que resulta fundamental para comprender la importancia de esta disputa es que cada clasificación tiene consecuencias concretas para la vida de estas personas. En tanto el territorio sobre el que se encuentran construidas sus viviendas continúe siendo clasificado como un espacio contaminado o inhabitable, seguirán recibiendo acusaciones morales por permanecer en ese lugar. Pero, como señalamos anteriormente, dadas las características de la migración latinoamericana reciente hacia la ciudad de Córdoba, las posibilidades que estas personas tienen para habitar otros espacios son reducidas. La dificultad del acceso a la vivienda a través de los canales formales en un escenario de exclusiones y desigualdades sociales, permite comprender que para muchos vecinos de Los Pinos permanecer habitando esos terrenos se presente como una opción posible. Y de allí, la necesidad de disputar la clasificación de dicho espacio como "contaminado".

La noción de interés inmobiliario adquiere en este contexto una relevancia fundamental. La facción que quiere quedarse habitando Los Pinos manifiesta la convicción de que la tierra no estaría contaminada. Por el contrario, sostienen que esto se trata de un verso que formuló el Estado Municipal para 
ocultar los verdaderos intereses que tendría en estas tierras. Así, para esta facción la contaminación no refiere a la del suelo, sino a la manera en que los funcionarios definieron esta situación. En relación a esto, un vecino le explicaba a otro: "Mirá... Acá todos tienen un negociado. Más grande, más chico, pero todos sacan algún negocio. En la política es así, ¿viste?" De este modo, la contaminación de las relaciones es pensada en contraposición a un deber ser que tendría que definir la relación entre los políticos y los vecinos. Las características que los procesos de urbanización han presentado históricamente en la provincia de Córdoba permiten comprender el peso que la noción de interés inmobiliario adquiere en esta disputa pues, en tanto el espacio se encuentra lejos de ser transparente, es preciso atender a la sedimentación de épocas anteriores (Lefebvre 1974). Sólo entendiendo que históricamente en esta provincia el Estado jugó un papel importante en la planificación urbana facilitando terrenos al sector inmobiliario privado se puede comprender que esta disputa en particular gire en torno a la posibilidad de que la contaminación sea un verso.

Podemos afirmar entonces que esta disputa por la clasificación de la categoría de contaminación constituye una lucha política en sí misma y se relaciona con la posición que asume cada uno en relación a las facciones. Si pensamos a la política como la explica Bourdieu (1999), en términos de una lucha por imponer la propia visión de la realidad social como la visión legítima, se comprende que la disputa en torno a la definición de la categoría de contaminación puede pensarse en términos políticos. Si lo específico de la política refiere a "su condición de proceso social de definición y redefinición de sentidos, en el cual se produce y despliega una serie de representaciones sociales - valores, reglas, repertorios simbólicos, etc." (Rosato y Balbi 2003: 14), este conflicto puede entenderse en esos términos. Y es que, en definitiva, a través de la lucha por imponer una clasificación acerca del terreno en el que habitan y por definir a qué hace alusión ese concepto de contaminación, los vecinos despliegan aquellos valores, reglas y representaciones de sí mismos y de los otros que consideran legítimos.

\section{CONSIDERACIONES FINALES}

Como señala Mary Douglas (2002 [1966]: 53), las nociones de contaminación y de riesgo no constituyen realidades objetivas, sino que son el producto de una construcción social e históricamente situada. Estos conceptos no refieren a hechos aislados sino que están construidos sobre "una sistemática ordenación y clasificación de la materia, en la medida en que el orden implica el rechazo de elementos inapropiados". Por esto, la noción de contaminación que construyen las personas está en estrecha relación con los sistemas simbólicos de una sociedad y particularmente incluye aquellos elementos que son rechazados por 
éstos. Así, "nuestro comportamiento de contaminación es la reacción que condena cualquier objeto o idea que tiende a confundir o a contradecir nuestras preciadas clasificaciones" (Douglas 2002 [1966]: 54).

Históricamente en Argentina, estos sistemas simbólicos vincularon la pobreza a la contaminación, asociando "a los pobres con el caos, el desorden y la contaminación, presumiendo que ellos habitan un universo puramente físico, centrado en la actividad práctica y el interés utilitario" (Carman 2011: 20). En este marco, los desplazados se vuelven simbólicamente cada vez más impuros, perpetuándose entonces la segregación (Carman 2011).

Frente a tal coyuntura entendemos que no es que estas personas sean ignorantes o no comprendan los riesgos de la contaminación sino que, para ellos, el problema no radica allí. Como observamos, las distintas facciones se apropian de la categoría de contaminación de diferentes maneras a fin de fundamentar sus propias prácticas. Mientras que para el Estado y aquellos que se quieren ir, la contaminación aparece como un peligro obvio; para quienes se quieren quedar la situación es diferente. Frente a la supuesta contaminación del espacio, estos vecinos argumentan que el Estado y los políticos tendrían intereses en sus tierras. Intereses que, al permear las relaciones, estarían contaminándolas. Así, a la contaminación de las tierras, quienes quieren permanecer habitando Los Pinos oponen la contaminación de las relaciones.

Teniendo en cuenta lo desarrollado hasta aquí, uno de los aportes de este trabajo consiste en mostrar que el proceso analizado puede comprenderse como una lucha política que forma parte de una disputa desplegada por los sectores populares para desmarcarse de la mirada hegemónica y estigmatizante que, al vincular contaminación y pobreza, los ubica a ellos mismos como "contaminados". Como señala Douglas (2002 [1966]), aquello que es visto como riesgoso constituye un medio de control político y social. En pos de mantener una forma de vida social que resulte funcional al grupo dominante, el Estado atribuye la connotación de contaminación y de riesgo a la situación atravesada por Los Pinos. Al acusarlos de ignorantes por querer permanecer habitando el barrio, se da entonces una inculpación de las víctimas en la búsqueda de legitimar que el riesgo existe y está bien establecido, de modo que si ellos lo sufren es porque no acataron las normas. La sanción moral que se construye tanto desde el dispensario como desde la de la asistenta social y los medios de comunicación constituye entonces una parte fundamental del control que el Estado busca ejercer sobre los modos de vida de los diferentes grupos.

Otro de los aportes que podemos realizar analizando lo trabajado hasta acá a la luz de la perspectiva de Douglas, es que "inculpar a la víctima es eficaz para silenciar denuncias de la totalidad del sistema social" (2002 [1966]): 93). Aquello que se pierde de vista en este conflicto son las condiciones estructurales que llevan a que algunas personas deban justificar su elección de vivir 
en estos espacios. La definición de este espacio, como contaminado o no, se encuentra en disputa porque supone consecuencias materiales importantes para las personas que allí viven.

Trabajar desde la perspectiva etnográfica nos permitió problematizar aquello que sucede hacia el interior de los barrios que se ven atravesados por programas relativos a la urbanización. En este sentido, pusimos de relieve que, frente a las políticas públicas de vivienda, los sujetos asumen posiciones diferentes de acuerdo a sus trayectorias y posibilidades concretas de luchar por viviendas, de manera que surgen también disputas para intervenir en el proceso de decisión. Mostramos cómo los sujetos de sectores populares son capaces de disputar con el Estado por el poder de decisión. Este trabajo puede servir entonces para poner en discusión, en el terreno gubernamental y de las políticas públicas, otra forma de entender y abordar estos conflictos sociales.

\section{BIBLIOGRAFÍA}

AUYERO, Javier, 2007, “Introducción: claves para pensar la marginación”, en Loïc Wacquant, Parias Urbanos: Marginalidad en la Ciudad a Comienzos del Milenio. Buenos Aires, Ediciones Manantial, 9-31.

AUYERO, Javier, y Débora SWISTUN, 2007, "Expuestos y confundidos: un relato etnográfico sobre el sufrimiento ambiental”, Iconos: Revista de Ciencias Sociales, 28: 137-152.

BERMÚDEZ, Natalia, 2009, "Los pobres no tienen gusto... Construcción política del espacio y violencia simbólica", Prácticas de Oficio: Investigación y Reflexión en Ciencias Sociales, 5, disponible en < www.ides.org.ar/wp-content/uploads/2012/04/artic17.pdf > (última consulta en septiembre de 2014).

BOIXADÓS, María C., 2000, Las Tramas de Una Ciudad. Córdoba entre 1870 y 1895: Élite Urbanizadora, Infraestructura, Poblamiento... Córdoba, Ferreyra Editor.

BOURDIEU, Pierre, 1999, "Violencia simbólica y luchas políticas", en Pierre Bourdieu, Meditaciones Pascalianas. Barcelona, Editorial Anagrama, 215-271.

CALDEIRA, Teresa, 2007, Ciudad de Muros. Barcelona, Gedisa Editorial.

CALDEIRA, Teresa, 2011, Espacio, Segregación y Arte Urbano en Brasil. Buenos Aires, Katz Editores.

CARMAN, María, 2011, Las Trampas de la Naturaleza: Medio Ambiente y Segregación en Buenos Aires. Buenos Aires, Fondo de la Cultura Económica.

DOUGLAS, Mary, 2002 [1966], Pureza y Peligro: Un Análisis de los Conceptos de Contaminación y Tabú. Buenos Aires, Ediciones Nueva Visión.

FALCÓN AYBAR, María del Carmen, y Eduardo BOLOGNA, 2013, "Migrantes antiguos y recientes: una perspectiva comparada de la migración peruana a Córdoba, Argentina", Migraciones Internacionales, 7 (1): 235-266. 
LACARRIEU, Mónica B., y Guy THUILLIER, 2001, "Las urbanizaciones privadas en Buenos Aires y su significación”, Revista Perfiles, 19: 83-113.

LEFEBVRE, Henri, 1974, "La producción del espacio", Papers: Revista de Sociologia, 3: 219 229.

LENOIR, Remy, 1993, “Objeto sociológico y problema social”, en Patrick Champagne et al., Iniciación a la Práctica Sociológica. Madrid, Siglo Veintiuno Editores, 57-102.

LUHMANN, Niklas, 1992, Sociología del Riesgo. México, Universidad Iberoamericana/Universidad de Guadalajara.

MARCUSE, Peter, y Ronald VAN KEMPEN, 2000, Globalizing Cities: A New Spatial Order. Oxford, Blackwell Publishers.

Merklen, Denise, 2005, Pobres Ciudadanos: Las Clases Populares en la Era Democrática (Argentina 1983-2003). Buenos Aires, Editorial Gorla.

PALMEIRA, Moacir, 2003, "Política, facciones y votos", en Fernando Balbi y Ana Rosato (orgs.), Representaciones Sociales y Procesos Políticos: Estudios desde la Antropología Social. Buenos Aires, Editorial Antropofagia, 3 1-44.

PAYRÓ, Jimena, y Josefina MONTOYA, 2007, "Las ciudades invisibles: significados sobre el espacio habitado desde las concepciones de los actores, el caso de Villa La Maternidad", presentado en las XII Jornadas de la Red Nacional de Investigadores en Comunicación, Rosario, 16, 17 y 18 de octubre de 2007.

PRÉVÔT SCHAPIRA, Marie-France, 2001, "Fragmentación espacial y social: conceptos y realidades", Perfiles Latinoamericanos, 19: 33-56.

ROSATO, Ana, y Fernando BALBI, 2003, “Introducción”, en Fernando Balbi y Ana Rosato (orgs.), Representaciones Sociales y Procesos Políticos: Estudios desde la Antropología Social. Buenos Aires, Editorial Antropofagia, 1 1-27.

SCHTEINGART, Martha, 2001 [1990], Los Productores del Espacio Habitable: Estado Empresa y Sociedad en la Ciudad de México. México, El Colegio de México.

SEGATO, Rita, 2006, "En busca de un léxico para teorizar la experiencia territorial contemporánea”, Politika: Revista de Ciencias Sociales, 2: 129-148.

TERRONES RIBAS, Albert, 2005, "Política social y exclusión residencial de las mujeres inmigrantes en Madrid y Barcelona”, en Carlota Solé y Lluis Flaquer (orgs.), El Uso de las Politicas Sociales por las Mujeres Inmigrantes. Madrid, Instituto de la Mujer (Ministerio de Trabajo y Asuntos Sociales), 193-298. 